\title{
Protective effects of peel extracts of Irvingia wombolu on metabolic disorders in streptozotocin-induced diabetic rats
}

\author{
Rosane Soh Matsinkou ${ }^{1,2^{*}}$ D, Valere Aime Soh Oumbe ${ }^{3}$, Judith Laure Ngondi $^{2}$ and Julius Enyong Oben ${ }^{2}$
}

\begin{abstract}
Background: Diabetes is widely recognized as associated with several structural and functional liver, kidney, and heart abnormalities. Therefore, the present study was conducted to evaluate the protective effect of peel extracts of Irvingia wombolu against diabetes complications.

Methods: Diabetes was induced by intravenous administration of streptozotocin (STZ) $(50 \mathrm{mg} / \mathrm{kg})$ through the right jugular vein on rats and animals with blood glucose values of at least $250 \mathrm{mg} / \mathrm{dl}$ received orally aqueous extract of peel (AEP), hydroethanolic extract of peel (HEP), tolbutamide and DMSO 10\%. Their effects on the concentration of blood glucose, total cholesterol, HDL-C, LDL-C, triglycerides, malondialdehyde (MDA) and activities of catalase (CAT), reduced glutathione (GSH), superoxide dismutase (SOD), aspartate aminotransferase (AST), and alanine aminotransferase (ALT) in diabetic and normal rats were investigated using standard methods.

Results: Twenty-one days of treatment with AEP and HEP at a dose of $400 \mathrm{mg} / \mathrm{kg}$ significantly $(P<0,05)$ reduced the fasting blood glucose to a point of reaching normal value. The antihyperlipidemic assessment of extracts revealed a significant $(P<0,05)$ decrease in total cholesterol, triglycerides, LDL levels, and a significant $(P<0,05)$ increase in HDL level in the plasma of treated diabetic rats. Furthermore, plasma biomarkers of liver and kidney dysfunction were significantly reduced in treated diabetic rats. We also observed increased activities of catalase, SOD, and reduced glutathione in diabetic treated rats.

Conclusion: The present findings suggest that AEP and HEP have a protective effect on liver, kidney, and heart in experimental diabetic rats which can be beneficial in the management of diabetes and its complications.
\end{abstract}

Keywords: Diabetes, Irvingia wombolu, Peel extracts, Protective effects, Rats, Streptozotocin

\section{Background}

Permanent hyperglycemia is a leading cause of diabetes mellitus (DM) which is a chronic metabolic disorder that can cause damages in all systems in the body if not treated. It is a major global public health problem with an escalating incidence and prevalence particularly in

\footnotetext{
* Correspondence: mrosane@yahoo.com

'Department of Food Sciences and Nutrition, University of Ngaoundere, Laboratory of Biophysic Food Biochemistry and Metabolism, ENSAl, PO. Box: 455, Ngaoundere, Cameroon

2Department of Biochemistry, University of Yaounde I, Laboratory of Nutrition and Nutritional Biochemistry, PO. Box: 812, Yaounde, Cameroon Full list of author information is available at the end of the article
}

developing and newly industrialized countries [1]. In 2016, 1.6 million diabetes-associated deaths were recorded, and currently, 422 million people live with diabetes related complications characterized by microvascular (retinopathy, neuropathy, and nephropathy) or macrovascular (myocardial infarction, heart failure, and stroke) diseases resulting from chronic exposure to high glucose and altered blood lipids $[2,3]$. Diabetes therapies are associated with the control of the signs and symptoms of the pathologies without promoting cure. The currently available treatment options for hyperglycemia, apart from lifestyle changes and weight reduction, are oral hypoglycemic agents with various

\section{Springer Open}

() The Author(s). 2020 Open Access This article is licensed under a Creative Commons Attribution 4.0 International License, which permits use, sharing, adaptation, distribution and reproduction in any medium or format, as long as you give appropriate credit to the original author(s) and the source, provide a link to the Creative Commons licence, and indicate if changes were made. The images or other third party material in this article are included in the article's Creative Commons licence, unless indicated otherwise in a credit line to the material. If material is not included in the article's Creative Commons licence and your intended use is not permitted by statutory regulation or exceeds the permitted use, you will need to obtain permission directly from the copyright holder. To view a copy of this licence, visit http://creativecommons.org/licenses/by/4.0/. 
modes of action and their effect on insulin [4]. The unavailability of these conventional drugs in many rural areas and their high cost coupled with their high incidence of side effects posed a real challenge for a change to alternative methods like medicinal plant sources. Recently, plant derived extracts or compounds were evaluated to have antidiabetic targets such as $\alpha$-glucosidase, $\alpha$-amylase, DPP-4, PPAR- $\gamma$, PTP1B, and GLUT4 [5].

In this study, we evaluated the activities of peel extracts of Irvingia wombolu which in previous studies have shown its richness in bioactive compounds which can inhibit free radicals and lipid peroxidation [6]. They also showed a protective effect in the induction of insulin resistance with a high-fat high-fructose (HFHF) diet reported by a lower increase in fasting blood glucose and triglycerides and post-prandial glycemic peak [7]. It was hypothesized that peel extracts of Irvingia wombolu may reduce blood sugar and lipids levels, and has the ability to protect against diabetes related complications like renal, hepatic, and cardiac failure. In this context, peel extracts of Irvingia wombolu were tested in the rat model of type I diabetes induced by streptozotocin.

\section{Methods}

\section{Plant material and extracts preparation}

Kernels of Irvingia wombolu were bought in October 2015 at the market of Mfoundi in the Centre region and capital city of Cameroon (Yaounde). They were washed to remove the peel. After drying in an oven at $50{ }^{\circ} \mathrm{C}$, peels were ground well to get fine powder and extracted by maceration with water and hydroethanol $(1: 1 \mathrm{v} / \mathrm{v})$ during $48 \mathrm{~h}$. Supernatants were obtained by filtration through Whatman paper No 3 and kept for evaporation in an oven at $50^{\circ} \mathrm{C}$ until complete drying. After drying, the sample was removed, blended into powder and stored in a desiccator for further manipulation.

\section{Chemicals}

All the chemicals used were of analytical grade and were purchased from sigma chemical Co., Louis, MO, USA.

\section{Animal}

The experimental procedures described below were approved by the institutional animal ethical committee. Thirty (30) male Wistar albino rats weighing 250-300 g were obtained from the animal house of the Department of Biochemistry, University of Yaounde I, Cameroon, and used for this study. The rats were housed and maintained at a $12 \mathrm{~h}$ light and dark cycle and fed with rat diet ad libitum. Streptozotocin (STZ) was dissolved in $0.1 \mathrm{M}$ cold citrate buffer, $\mathrm{pH} 4.5$, immediately before use. Diabetes was induced by intravenous administration of STZ $(50 \mathrm{mg} / \mathrm{kg})$ through the right jugular vein after an overnight fast. 25 rats were selected and used for the rest of the study, $72 \mathrm{~h}$ after diabetes has been established. The rats were divided into five groups of five rats each. One normal control group (only 10\% DMSO); one diabetic control group (only 10\% DMSO) and three other groups receiving respectively Tolbutamide $(80 \mathrm{mg} / \mathrm{kg}$ in $10 \%$ DMSO), an aqueous extract of peel, and hydroethanolic extract of the peel. The fasting blood glucose level was measured regularly using a glucometer (before, during, and after the experiment). To measure lipids and other parameters, oral administration was conducted daily for 21 days. After 21 days of treatment, the $12 \mathrm{~h}$-fasted animals were sacrificed by cervical decapitation. Blood samples were collected from the jugular vein into EDTA tubes and centrifuged at $3000 \mathrm{rpm}$ for $10 \mathrm{~min}$ to obtain the plasma which was stored at $-20^{\circ} \mathrm{C}$ for the measurement of biochemical parameters. Tissues (liver, kidney, and heart) were collected, washed with saline solution and homogenate prepared in sodium chloride (0.9\%). After centrifugation at $3000 \mathrm{rpm}$ for $10 \mathrm{~min}$, the supernatant was stored at $-20^{\circ} \mathrm{C}$ until analysis. Erythrocyte suspension was made by washing blood residue three times with sodium chloride and followed by lyses with water and stored in the freezer at $-20{ }^{\circ} \mathrm{C}$ for further uses.

\section{Biochemical analysis}

Triglycerides were estimated by the GOP-PAP method [8], total cholesterol by the CHOD-PAP method [9], and HDL cholesterol by the CHOD-PAP method [10].

Lipid peroxidation was determined spectrophotometrically by measuring the level of malondialdehyde and hydroperoxide (MDA) [11, 12]. Alanine aminotransferase (ALT) and aspartate aminotransferase (AST) were determined by the method of Reitman and Franckel (1957) and creatinine by the method of Bartels et al (1972) [13, 14]. The activity of enzymatic antioxidant, catalase was assayed spectrophotometrically based on the methods of Sinha (1972) [15]. Reduced Glutathione activity was assayed by the methods of Ellman (1959) [16]. Superoxide dismutase activity was assayed using the methods described by Misra and Fridovish (1972) [17].

\section{Data analysis}

All values were recorded in triplicate and represented as the mean \pm standard deviation in each group of rats. Differences between means were assessed using the KruskalWallis test following by the post hoc of Bonferonni with $P$ values at 0.05 significance levels.

\section{Results}

\section{Glycemic status of the models}

Fasting blood glucose (FBG) levels were comparable within normal models and diabetic models on day 0 . After treatments for 21 days, the corresponding FBG 
level decreased significantly in the diabetic rats receiving AEP and HEP to a point of reaching normal value [ $(453.25 \pm 30.6$ and $436.8 \pm 33.7 \mathrm{mg} / \mathrm{dl})$ day 0 vs $(62.66 \pm$ 12.2 and $82.4 \pm 11 \mathrm{mg} / \mathrm{dl}$ ) day 21 respectively] (Table 1 ).

Effect of peel extracts of Irvingia wombolu on lipid profile Results showed the untreated diabetic animals with a significant increase $(P<0.05)$ in LDL-C and TG and among others with a significant decrease $(P<0.05)$ in HDL-C. Administration of plant extracts leads to a significant decrease $(P<0.05)$ in TC, LDL-C, and TG, and the best effect was obtained with HEP which also showed a significant increase $(P<0.05)$ in HDL-C as the best, and has a better effect than the tolbutamide (Table 2).

Treatment of diabetic rats with peel extracts resulted in a significant decrease $(P<0.001)$ in the atherogenic indices (Table 3). The effect was more marked with the HEP.

The extracts protect more than $80 \%$ against atherogenic risk. Regardless of the atherogenic indices used, the best protection was obtained with HEP (Table 4).

\section{Effect of peel extracts of Irvingia wombolu on parameters of oxidative lipid damage}

No variation in the level of MDA is observed in the plasma. However, the levels of hepatic and renal MDA have increased significantly $(P<0.05)$ in diabetic rats receiving no treatment. Treatment of diabetic animals with peel extracts resulted in a significant decrease $(P<0.05)$ in the MDA level from $59.22 \%$ (HEP) to $60.41 \%$ (AEP) in the liver and $62.41 \%$ (HEP) to $73.56 \%$ (AEP) in the kidneys. At the cardiac level, no effect of the extracts has been observed because the level of MDA remains high. It should be noted that the extracts work in the same direction as Tolbutamide (Table 5).

The evaluation of the levels of hepatic, renal, and cardiac hydroperoxides in diabetic rats has indicated that all the diabetics treated, have a significantly low level of hydroperoxides $(P<0.05)$ compared to the untreated diabetics. This decrease ranges from $58.58 \%$ (AEP) to $56.56 \%$ (HEP) in the liver and from $66.78 \%$ (HEP) to

Table 1 Effect of peel extracts of I. Wombolu on the glucose levels $(\mathrm{mg} / \mathrm{dl})$ after 21 days of treatment

\begin{tabular}{llll}
\hline Groups & Day 0 & Day 14 & Day 21 \\
\hline Control & $74,5 \pm 2,9$ & $72,25 \pm 2$ & $73,35 \pm 1,9$ \\
Diabetic control & $347,2 \pm 43,9^{\mathbf{a}}$ & $288 \pm 22^{\mathbf{a}}$ & $205,56 \pm 45,1^{\mathbf{a}}$ \\
Diabetic + tolbutamide & $278 \pm 29,4^{*}$ & $131 \pm 2,9^{*}$ & $62,4 \pm 6,3^{*}$ \\
Diabetic + AEP & $453,25 \pm 30,6^{*}$ & $189 \pm 36,6^{*}$ & $62,66 \pm 12,2^{*}$ \\
Diabetic + HEP & $436,8 \pm 33,7^{*}$ & $71 \pm 6,1^{*}$ & $82.4 \pm 11^{*}$
\end{tabular}

Values are expressed as mean $\pm \mathrm{SD}(n=5) ;{ }^{a}$ Values are statistically significant at $p<0.05$ compared to normal control rats; * Values are statistically significant at $p<0.05$ compared to diabetic control rats. AEP Aqueous extract of peel, HEP Hydroethanolic extract of peel.
65.73\% (AEP) in the kidney. At the heart level, only the reference medicine caused a decrease in the level of hydroperoxides of around $19.49 \%$ (Table 6).

\section{Effect of peel extracts of Irvingia wombolu on parameters of toxicity}

It appears that the diabetic state has caused damage to the hepatic level characterized by a significant increase in the levels of transaminases. The ALT and AST level are 1.2 and 1.4 times higher than that of the normal control, respectively. We also observed an increase in the creatinine level in diabetic control 3 times greater than the normal control value. These increases in some test groups were not significantly $(p>0.05)$ different from those of the tolbutamide groups while others better increase than the tolbutamide groups and than that of the normal control, demonstrating renal damage. The administration of AEP and HEP resulted in a significant decrease $(p<0.001)$ in the level of these parameters so that it is comparable to Tolbutamide, used as the reference (Table 7).

The reduced glutathione (RG) levels in untreated diabetic rats are low at the level of the hemolysate. On the other hand, at the organ level (liver, kidney, heart), the level of RG is found to be high. It should be noted that these observations are made relative to the negative control group. At the level of the hemolysate, administration of peel extracts and tolbutamide lead to a significant increase $(p<0.001)$ of the GSH of about $2.36 ; 2.21$; and 1.23 times, respectively, for AEP, HEP, and tolbutamide compared to untreated diabetic rats. Indeed, these extracts worked better than the reference medicine. At the organ level, by comparing untreated diabetics to diabetics treated with our plant extracts and tolbutamide, we find that the administration of the extracts and the reference drug leads to a significant increase of the level of reduced glutathione $(p<0.01)$ except in the kidney where only the reference medicine (tolbutamide) works (Table 8).

The diabetic state led to a depletion of the activities of SOD and catalase expressed by a significant decrease $(p<0.001)$ in their activity at the erythrocyte level. The administration of AEP and HEP results in a significant increase in SOD and erythrocyte catalase activities compared to untreated diabetics (Table 9).

The diabetic state has no effect on the activity of catalase in the liver but we observed a significant decrease in this activity in the heart. AEP significantly increased the activity of catalase in the liver and in the heart compared to untreated diabetics. HEP only acts in the heart by increasing the activity of catalase. Tolbutamine has no significant effect on catalase activity in the liver and heart (Table 10). 
Table 2 Effect of peel extracts of I. wombolu on lipid profile

\begin{tabular}{lllll}
\hline Groups & TC $(\mathbf{m g} / \mathbf{d l})$ & LDL-C $(\mathbf{m g} / \mathbf{d l})$ & HDL-C $(\mathbf{m g} / \mathbf{d l})$ & TG $(\mathbf{m g} / \mathbf{d l})$ \\
\hline Control & $74.05 \pm 5.58$ & $24.54 \pm 9.80$ & $23.84 \pm 9.39$ & $46 \pm 2.68$ \\
Diabetic control & $85.07 \pm 6.88$ & $55.84 \pm 9.51 \mathrm{a}$ & $1.21 \pm 0.13 \mathrm{a}$ & $160.70 \pm 11.96 \mathrm{a}$ \\
Diabetic + tolbutamide & $32.85 \pm 4.84^{*}$ & $11.38 \pm 3.12^{*}$ & $8.44 \pm 5.64^{*}$ & $27.73 \pm 17.09^{*}$ \\
Diabetic + AEP & $59.79 \pm 13.44^{*}$ & $30.15 \pm 9.98^{*}$ & $7.17 \pm 3.18^{*}$ & $41 \pm 13.12^{*}$ \\
Diabetic + HEP & $56.30 \pm 23.41^{*}$ & $37.39 \pm 16.67^{*}$ & $13.25 \pm 4.28^{*}$ & $37.10 \pm 16.79^{*}$
\end{tabular}

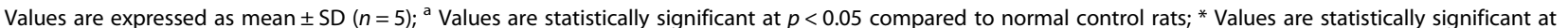
$p<0.05$ compared to diabetic control rats. AEP Aqueous extract of peel, HEP Hydroethanolic extract of peel.

\section{Discussion}

Peel extracts of Irvingia wombolu were evaluated for their hypoglycemic and antihyperlipidemic activities via their improvement in blood glucose profile and their protective effect against liver, kidney, and heart failure in streptozotocin-induced diabetic rats as compared to the standard tolbutamide. The results of Table 1 indicated that intravenous injection of STZ destroyed beta cells and thus induced type I diabetes in rats in which glucose level significantly increased compared to controls. However, blood glucose levels were reduced in all experimental groups which received peel extracts or tolbutamide. The effective regulation of blood glucose concentration is a key step in preventing or reducing diabetic complications and improving the quality of life in type 1 and 2 diabetic patients [18]. Previous studies have shown that peel extracts of Irvingia wombolu are rich in phenolic compounds that could be related to the hypoglycemic effect observed in this study [6]. Phenolic compounds present in peel extracts may enhance glucose uptake and prevent hyperglycemia through several mechanisms such as increased inhibitory effects against insulinase, reduced hepatic inflammation, and improved insulin sensitivity [19-21]. As well as other mechanisms also involved such as inhibition of intestinal glucose absorption, enhanced peripheral glucose utilization, hepatic glycogen synthesis, or decrease of glycogenolysis [20-22].

Table 3 Effect of peel extracts of I. Wombolu on the atherogenic risk indices

\begin{tabular}{llll}
\hline Groups & TC/HDL-C & LDL-C/HDL-C & TG/HDL-C \\
\hline Control & $1.56 \pm 0.19$ & $0.44 \pm 0.17$ & $1.92 \pm 0.28$ \\
Diabetic control & $71.59 \pm 12 \mathrm{a}$ & $47.20 \pm 10.75 \mathrm{a}$ & $132.80 \pm 0.92 \mathrm{a}$ \\
Diabetic + tolbutamide & $5.06 \pm 2.05^{*}$ & $1.98 \pm 0.96^{*}$ & $3.2 \pm 3.03^{*}$ \\
Diabetic + AEP & $9.04 \pm .3 .03^{*}$ & $4.51 \pm 1.13^{*}$ & $5.71 \pm 4.12^{*}$ \\
Diabetic + HEP & $4.58 \pm 2.13^{*}$ & $3.07 \pm 1.70^{*}$ & $2.8 \pm 3.92^{*}$
\end{tabular}

Values are expressed as mean \pm SD $(n=5) ;{ }^{\text {a }}$ Values are statistically significant at $p<0.05$ compared to normal control rats; ${ }^{*}$ Values are statistically significant at $p<0.05$ compared to diabetic control rats. AEP Aqueous extract of peel, HEP hydroethanolic extract of peel.
To reduce the risk of late complications and negative outcomes of diabetes mellitus, such as blindness, renal failure, and limb amputation, the control not only of blood glucose levels but also lipid levels is necessary [23]. Insulin deficiency causes hyperglycemia and mobilization of fatty acids from adipose tissue. Fatty acids are mobilized from adipose tissue to cover energy needs. Thus, excess fatty acids are accumulated in the liver and converted into triglycerides, thereby contributing to an increase in the plasma triglyceride level [24]. Diabetic patients also have an increased risk of developing heart failure because of the abnormal cardiac handling of glucose and free fatty acids (FFAs), and because of the effect of the metabolic derangements of diabetes on the cardiovascular system [25]. The peel extracts did not show any direct effect on total cholesterol in the study as shown in Table 2 . However, we observed a significant decrease in the level of TC, LDL-C, TG, and a significant increase level of HDL-C after administration of these extracts. Table 3 gives us information about the atherogenic risk factor. Most of the plant treated groups showed a reduced ratio of these indices mainly TG/ HDL-C ratio. TG/HDL-C ratio could predict accurately the risk for coronary heart diseases (CHD) and cardiovascular diseases (CVD) mortality [26, 27]. HEP shows the best percentage of protection (93\%) against atherogenic risk indices as shown in Table 4. These results are in good correlation with earlier reports, which stated that high triglycerides with low HDL-C lead to diabetes onset [28]. The results obtain which peel extracts on lipid profile was probably due to the presence of several secondary metabolites and their synergistic properties on this plant.

Table 4 Percentage of protection of peel extracts against atherogenic risk indices

\begin{tabular}{lll}
\hline Groups & $\begin{array}{l}\text { Protection (\%) } \\
\text { (TC/C-HDL) }\end{array}$ & $\begin{array}{l}\text { Protection (\%) } \\
\text { (C-LDL/C-HDL) }^{\mathbf{A}}\end{array}$ \\
\hline Diabetic + Tolbutamide & 92,91 & 95,79 \\
Diabetic + AEP & 87,36 & 90,29 \\
Diabetic + HEP & 93,69 & 93,49
\end{tabular}

AEP Aqueous extract of peel, $H E P$ Hydroethanolic extract of peel ${ }^{\mathrm{A} P r o t e c t i o n}(\%$ ) $=\frac{\text { atherogenic Indice of negative control }- \text { atherogenic Indice of treated group }}{\text { atherogenic Indice of positive control }} \times 100$ 
Table 5 Effect of peel extracts of I. Wombolu on the level of MDA in plasma, liver, kidney, and heart

\begin{tabular}{lllll}
\hline Groups & & \multicolumn{3}{l}{ Lever of $\boldsymbol{M D A}(\boldsymbol{\mu} \boldsymbol{M} / \boldsymbol{g}$ of tissue) } \\
\cline { 3 - 5 } & Plasma $(\boldsymbol{\mu M})$ & Liver & kidney & Heart \\
\hline Control & $1,55 \pm 0,24$ & $3,52 \pm 0,22$ & $4,02 \pm 0,46$ & $1,24 \pm 0,10$ \\
Diabetic control & $2,29 \pm 1,14$ & $6,72 \pm 0,24^{\mathbf{a}}$ & $5,56 \pm 0,16^{\mathbf{a}}$ & $2,16 \pm 0,30^{\mathbf{a}}$ \\
Diabetic + tolbutamide & $1,67 \pm 0,61$ & $2,98 \pm 0,72^{*}$ & $1,83 \pm 0,36^{*}$ & $2,22 \pm 0,41$ \\
Diabetic + AEP & $1,59 \pm 0,98$ & $2,66 \pm 0,58^{*}$ & $1,47 \pm 0,25^{*}$ & $2,50 \pm 0,63$ \\
Diabetic + HEP & $1,70 \pm 0,48$ & $2,74 \pm 0,65^{*}$ & $2,09 \pm 0,17^{*}$ & \\
\hline
\end{tabular}

Values are expressed as mean $\pm \mathrm{SD}(n=5) ;{ }^{a}$ Values are statistically significant at $p<0.05$ compared to normal control rats; ${ }^{*}$ Values are statistically significant at $p<0.05$ compared to diabetic control rats. AEP Aqueous extract of peel, HEP Hydroethanolic extract of peel.

Lipid peroxidation is a natural phenomenon involved in the peroxidative loss at unsaturated lipids, thus bringing about lipid degradation and membrane disorganization. Peroxidised lipid has been considered to play a significant role in the pathogenesis of several diseases and may be taken as a molecular mechanism of cell injury under pathological conditions [29]. Lipid peroxidation is usually measured through its catabolite malondialdehyde (MDA) as a marker of oxidative stress [30]. A marked increase in the concentration of MDA and hydroperoxides in STZinduced diabetic rats as shown in Tables 5 and 6 indicated enhanced lipid peroxidation leading to tissue injury and failure of the antioxidant defense mechanism to prevent the formation of excess free radicals. AEP and HEP significantly $(P<0.05)$ reduced the MDA and hydroperoxide levels in the liver, kidney, and heart as compared to diabetic control. These results suggesting that peel extracts act to protect vital tissues such as the liver, the kidney, and the heart thereby reduce the risk of complications related to diabetes. The same result was obtained by Siva et al., (2010) in the liver and kidney when working on the antidiabetic and antioxidant potential of S. mahagoni bark [31].

ALT and AST are cytosolic enzymes reflecting hepatic necrosis. When the liver cells get damaged or injured,

Table 6 Effect of peel extracts of I. wombolu on hydroperoxides level (mM hydroperoxides / $100 \mathrm{~g}$ of tissue) liver, kidney, and heart

\begin{tabular}{llll}
\hline Groups & \multicolumn{2}{l}{ Organs } \\
\cline { 2 - 4 } & Liver & Kidney & Heart \\
\hline Control & $2.05 \pm 0.03$ & $1.68 \pm 0.04$ & $0.84 \pm 0.21$ \\
Diabetic control & $1.98 \pm 0.13$ & $2.86 \pm 0.15^{\mathbf{a}}$ & $1.18 \pm 0.11^{\text {a }}$ \\
Diabetic + tolbutamide & $1.69 \pm 0.24$ & $2.32 \pm 0.32^{*}$ & $0.95 \pm 0.22^{*}$ \\
Diabetic + AEP & $0.82 \pm 0.18^{*}$ & $0.98 \pm 0.42^{*}$ & $1.45 \pm 0.15^{*}$ \\
Diabetic + HEP & $0.86 \pm 0.13^{*}$ & $0.95 \pm 0.24^{*}$ & $1.38 \pm 0.18^{*}$
\end{tabular}

Values are expressed as mean $\pm \mathrm{SD}(n=5) ;{ }^{\text {a }}$ Values are statistically significant at $p<0.05$ compared to normal control rats; * Values are statistically significant at $p<0.05$ compared to diabetic control rats. AEP Aqueous extract of peel, HEP Hydroethanolic extract of peel. these enzymes are found into the blood flow, raising their percentage in blood levels. Hence raised blood levels of AST and ALT mean liver disease or injury. The results observed in Table 7 show diabetic rats with high AST and ALT levels confirming liver damage which can be rectified significantly by AEP and HEP treatment. Monalisa et al., (2018) also obtained this result by working on the hepatoprotective and nephroprotective activity of eucalyptus oil on Streptozotocin-induced diabetic mice [32]. Diabetes mellitus affects the kidney and is the leading cause of diabetic nephropathy. Patients with chronic liver disease have a significantly lower serum creatinine concentration than the general population $[33,34]$. Elevated creatinine of the plasma treated with STZ can be observed in Table 7 and a reduced level of this kidney waste product was acquired by treating the model with AEP and HEP.

Creatinine is a biological parameter generally used in testing nephroactivity as they are the chief indicator of kidney function. Abnormally high levels of creatinine give a warning of possible malfunction or failure of the kidney. This capacity of the extracts to act on the renal and hepatic levels is probably due to their antioxidant properties and their hypoglycemic effect. Hyperglycemia is the main factor involved in the induction of diabetic nephropathy [35].

Indirectly, hyperglycemia is the cause of GSH depletion and these results in oxidative stress [36]. A decrease in GSH levels could signify an increased utilization due to oxidative stress and elevated activity of GSH protection of cellular proteins against oxidation through the glutathione redox cycle, which could also directly detoxify reactive oxygen species the generated from exposure to STZ [37]. Several studies have reported a decrease in GSH levels as an indicator of oxidative stress in diabetic conditions [36, 38, 39]. However, this study showed a significant reduction in the GSH levels of diabetic control only in hemolysate and a significant increase of these levels in the liver, kidney, and heart compared to the normal control group. Administration of peel extracts significantly increased the GSH level in hemolysate, 


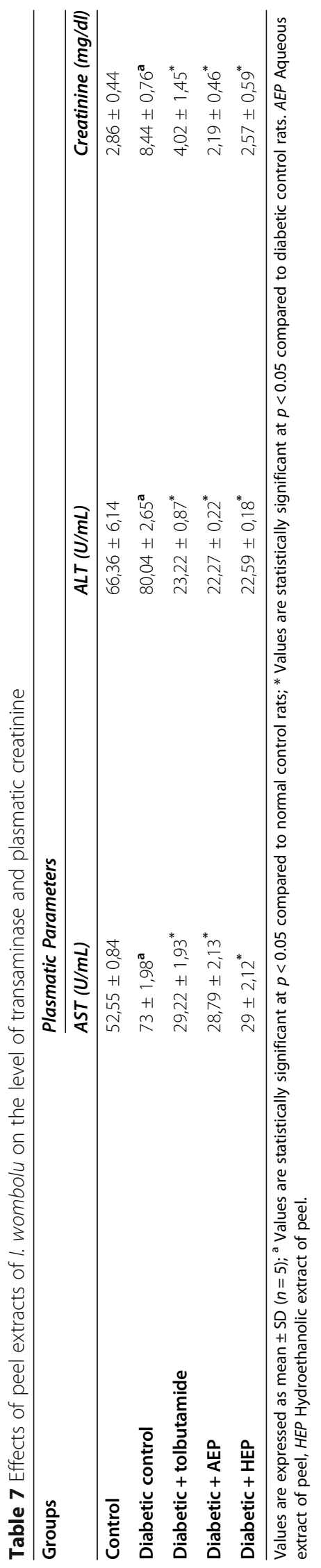




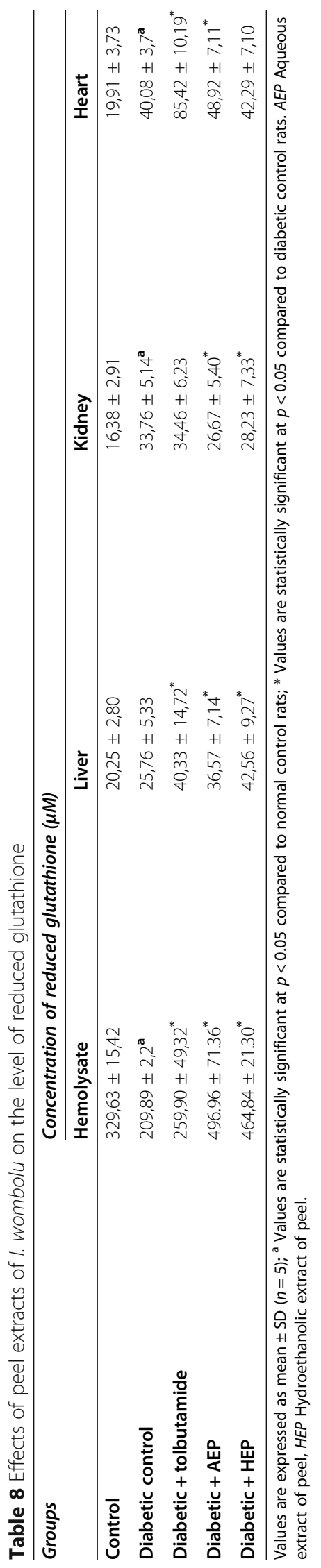


Table 9 Effects of peel extracts of I. wombolu on the erythrocyte activities of SOD and catalase

\begin{tabular}{lll}
\hline Groups & \multicolumn{2}{l}{ Parameters } \\
\cline { 2 - 3 } SOD (U/mg of protein) & $\begin{array}{l}\text { Catalase }(\mathbf{U} / \mathbf{m g} \\
\text { of protein) }\end{array}$ \\
\hline Control & $0,63 \pm 0,11$ & $131,80 \pm 15,40$ \\
Diabetic control & $0,11 \pm 0,01^{\text {a }}$ & $13,30 \pm 2,72^{\mathbf{a}}$ \\
Diabetic + tolbutamide & $0,12 \pm 0,005$ & $9,47 \pm 2,06$ \\
Diabetic + AEP & $0,28 \pm 0,04^{*}$ & $33,48 \pm 4,45^{*}$ \\
Diabetic + HEP & $0,20 \pm 0,03 b^{*}$ & $23,65 \pm 7,79^{*}$ \\
\hline
\end{tabular}

Values are expressed as mean $\pm \mathrm{SD}(n=5) ;{ }^{\text {a }}$ Values are statistically significant at $p<0.05$ compared to normal control rats; ${ }^{*}$ Values are statistically significant at $p<0.05$ compared to diabetic control rats. AEP Aqueous extract of peel, HEP Hydroethanolic extract of peel.

liver, kidney, and heart compared to diabetic control and thus protecting the liver, kidney, and heart from oxidative stress induced by STZ.

Catalase (CAT) is a heme-containing enzyme widely distributed in the peroxisomes or microperoxisomes of all animal tissues. This enzyme catalyzes the decomposition of $\mathrm{H}_{2} \mathrm{O}_{2}$ to water and oxygen, and thus protects the cell from oxidative damage by $\mathrm{H}_{2} \mathrm{O}_{2}$ or $\mathrm{OH}-$ [40]. It was found that CAT activity was decreased significantly in the erythrocyte, liver, and heart of the STZ-induced diabetic rats. Administration of AEP and HEP in diabetic rats showed a significant increase of the level of CAT compared to diabetic control, thus help to prevent oxidative injury of the liver and kidney. The best activity was attributed to AEP comparing to HEP and tolbutamide.

SOD catalyses the dismutation of superoxide radicals to hydrogen peroxide and molecular oxygen [41]. The location of SOD in the mitochondria and its position in the antioxidant chain make the enzyme to be particularly important as a slight decrease in SOD is sufficient to provoke cell damage [42]. In the present study, a significant decrease in the activity of SOD in the erythrocyte of diabetic control was observed compared with the normal control group and this could

Table 10 Effect of peel extracts of I. wombolu on the liver and heart catalase activity (U/mg of proteins)

\begin{tabular}{lll}
\hline Groups & \multicolumn{2}{l}{ Organs } \\
\cline { 2 - 3 } & Liver & Heart \\
\hline Control & $14,48 \pm 6,11$ & $40,70 \pm 3,83$ \\
Diabetic control & $14,22 \pm 2,37$ & $7,64 \pm 3,46^{\mathbf{a}}$ \\
Diabetic + tolbutamide & $11,31 \pm 2,54^{*}$ & $9,62 \pm 5,82$ \\
Diabetic + AEP & $15,48 \pm 8,59^{*}$ & $34,07 \pm 7,35^{*}$ \\
Diabetic + HEP & $9,98 \pm 1,68^{*}$ & $23,03 \pm 6,97^{*}$
\end{tabular}

Values are expressed as mean $\pm \mathrm{SD}(n=5) ;{ }^{a}$ Values are statistically significant at $p<0.05$ compared to normal control rats; ${ }^{*}$ Values are statistically significant at $p<0.05$ compared to diabetic control rats. AEP Aqueous extract of peel, HEP Hydroethanolic extract of peel. be due to an excessive formation of superoxide anions in diabetic rats. The results also showed that AEP and HEP were able to significantly increase the activity of SOD in diabetic rats. This means that the protective effect of peel extracts may act by either directly scavenging the reactive oxygen metabolites, due to the presence of various antioxidant compounds, or by increasing the synthesis of antioxidant molecules. These results are in agreement with the study of white tea extract supplementation in diabetic rats which showed an increase in the levels of antioxidants [43].

\section{Authors' contributions}

MATSINKOU SOH Rosane conceived and designed the study, carried out the experiments, analyzed and discussed the data and wrote the manuscript.

SOH OUMBE Valere Aime had been involved in revising this manuscript critically for important intellectual content. NGONDI Judith Laure and OBEN Julius Enyong were the major contributors in conceiving and designing the experiment. All authors read and approved the final manuscript.

\section{Funding}

This research did not receive any specific grant from funding agencies in the public, commercial, or not-for-profit sectors.

\section{Availability of data and materials}

The datasets used and/or analyzed during the current study are available from the corresponding author on reasonable request. All data generated or analyzed during this study are included in this published article.

Ethics approval and consent to participate

The experimental procedures described below were approved by the animal ethical committee of the Biochemistry Department, University of Yaounde I, Cameroon.

\section{Consent for publication \\ Not applicable.}

\section{Competing interests}

The authors have no conflicts of interest to declare regarding the publication of this paper.

\section{Author details}

${ }^{1}$ Department of Food Sciences and Nutrition, University of Ngaoundere, Laboratory of Biophysic Food Biochemistry and Metabolism, ENSAI, PO. Box: 455, Ngaoundere, Cameroon. ${ }^{2}$ Department of Biochemistry, University of Yaounde I, Laboratory of Nutrition and Nutritional Biochemistry, PO. Box: 812, Yaounde, Cameroon. ${ }^{3}$ Department of Biochemistry, University of Douala, Laboratory of Biochemistry, PO. Box: 24157, Douala, Cameroon.

Received: 9 June 2020 Accepted: 3 November 2020

Published online: 09 November 2020

\section{References}

1. Danaei G, Finucane MM, Lu Y, Singh GM, Cowan MJ, Paciorek CJ, et al. National, regional, and global trends in fasting plasma glucose and diabetes prevalence since 1980: systematic analysis of health examination surveys and epidemiological studies with 370 country-years and 2.7 million participants. Lancet. 2011;378(9785):31-40.

2. Alaboud AF, Tourkmani AM, Alharbi TJ, Alobikan AH, Abdelhay O, Batal SMA, et al. Microvascular and macrovascular complications of type 2 diabetic mellitus in central, Kingdom of Saudi Arabia. Saudi Med J. 2016; 37(12):1408-11.

3. Kosiborod M, Gomes MB, Nicolucci A, Pocock S, Rathmann W, Shestakova MV, et al. Vascular complications in patients with type 2 diabetes: prevalence and associated factors in 38 countries (the DISCOVER study program). Cardiovasc Diabetol. 2018;17(1):1-13. 
4. Eliasson B, Eeg-Olofsson K, Cederholm J, Nilsson PM, Gudbjornsdottir S. For the steering committee of the swedish national diabetes register. Antihyperglycaemic treatment of type 2 diabetes: results from a national diabetes register. Diabetes Metab. 2007;33:269-76.

5. Hea J-H, Chen L-X, Lia H. Progress in the discovery of naturally occurring anti-diabetic drugs and in the identification of their molecular targets. Fitoterapia. 2019 Apr;134:270-89.

6. Matsinkou SR, Dakam W, Azantsa Kingue BG, Ngondi JL. Julius Oben. Measurement of antioxidant activity of african mango (Irvingia wombolu) kernel peels. World J Pharm Res. 2017;6(4):148-62.

7. Ngondi JL, Matsinkou SR, Mbong Angie MA, Takussi NG, Oben JE. Preventive effect of Irvingia Wombolu pulp and Peel extracts against high fat-high fructose diet induced insulin resistance in rats. World J Pharm Res 2014;2(8):232-43.

8. Jacobs NJ, Vandermark PJ. The purification and properties of the alphaglycerophosphate oxidizing enzyme of Streptococcus faecalis 10C1. Arch Biochem Biophys. 1960;88(2):250-5.

9. Richmond W. Preparation and properties of a cholesterol oxidase from Nocardia sp. and its application to the enzymatic assay of Total cholesterol in serum. Clin Chem. 1973;19(12):1350-6.

10. Assmann G. Current diagnosis of hyperlipidemias. Internist (Berl). 1979; 20(11):559-64

11. Yagi K. A simple fluorometric assay for lipoperoxide in blood plasma. Biochem Med. 1976;15:212-6.

12. Jain SK, Palmera M. The effect of oxygen radicals metabolites and vitamin $E$ on glycosylation of proteins. Free Radical Bio Med. 1997;22(4):593-6.

13. Reitman FEN. Lipid oxidation. Prog Lipid Res. 1957;19:1-22.

14. Bartels $H$, Böhmer M, Heierli C. Serum creatinine determination without protein precipitation. Clin Chim Acta. 1972;37:193-7.

15. Sinha KA. Colorimetric assay of catalase. Anal Biochem. 1972;47:380-94.

16. George L. Ellman. Tissue sulfhydryl group. Arch Biochem Biophys. 1959;82: 70-7.

17. Misra HP, Fridovich I. The role of superoxide anion in the autoxidation of epinephrine and a simple assay for superoxide dismutase. J Biol Chem. 1972;247(10):3170-5

18. Abraira C, Colwell JA, Nuttall FQ, Sawin CT, Nagel NJ, Comstock JP, et al. Veterans affairs cooperative study on glycemic control and complications in type II diabetes (VA CSDM): results of the feasibility trial. Diabetes Care. 1995;18(8):1113-23.

19. Swain PK, Dinda SC, Nayak DP, Kar B, Patro VJ. Antioxidant activity of Enhydra fluctuans Lour. Aerial Parts J Phytother Pharmacol. 2012;1(2):23-34.

20. Kuri S, Billah MM, Rana SM, Naim Z, Islam MM, Hasanuzzaman M, et al. Phytochemical and in vitro biological investigations of methanolic extracts of Enhydra fluctuans Lour. Asian Pac J Trop Biomed. 2014;4(4):299-305.

21. Dua TK, Dewanjee S, Khanra R. Prophylactic role of Enhydra fluctuans against arsenic-induced hepatotoxicity via anti-apoptotic and antioxidant mechanisms. Redox Rep. 2016;21(4):147-54.

22. Satyajit DP. Natural flavonoids isolated from the leaves of Enhydra fluctuans inhibits cyclooxygenase-2 and 5-lipooxygenase inflammation in various models. Int J Res Pharmacol Pharmacotherapeut. 2012;1:65-71.

23. Ross R. The pathogenesis of atherosclerosis - an update. N Engl J Med. 1986;20:486-500.

24. Shih KC, Kwak CF, Hwa CM. Acipimox attenuates hypertriglyceridemia in dyslipidemic noninsulin dependent diabetes mellitus patients without perturbation of insulin sensitivity and glycemic control. Diabetes Res Clin Pract. 1997;36(2):113-9.

25. Rosano GM, Vitale C, Seferovic P. Heart failure in patients with diabetes mellitus. Card Fail Rev. 2017;3(1):52-5.

26. Jaganathan R, Ravindran R, Dhanasekaran S. Emerging role of adipocytokines in type 2 diabetes as mediators of insulin resistance and cardiovascular disease. Can J Diabetes. 2018;42(4):446-456.e1.

27. Vega GL, Barlow CE, Grundy SM, Leonard D, DeFina LF. Triglyceride-tohigh-density-lipoprotein-cholesterol ratio is an index of heart disease mortality and of incidence of type 2 diabetes mellitus in men. J Investig Med. 2014;62(2):345-9

28. Bitzur R, Cohen H, Kamari Y, Shaish A, Harats D. Triglycerides and HDL cholesterol: stars or second leads in diabetes? Diabetes Care. 2009;32(Suppl 2):S373-7.

29. Kuaimoto M, Inoue K, Nojima S. Effect of ferrous ion and ascorbate-induced lipid peroxidation on liposomal membranes. Biochim Biophys Acta Biomembr. 1981;646(1):169-78.
30. David R. Janero. Malondialdehyde and thiobarbituric acid-reactivity as diagnostic indices of lipid peroxidation and peroxidative tissue injury. Free Radical Bio Med. 1990;9(6):515-40.

31. Panda SP, Haldar PK, Bera S, Adhikary S, Kandar CC. Antidiabetic and antioxidant activity of Swietenia mahagoni in streptozotocin-induced diabetic rats. Pharm Biol. 2010;48(9):974-9.

32. Monalisa Chakraborty, Biswajoy Bagchi, Sukhen Das, Ruma Basu, Papiya Nandy. A dose dependent hepatoprotective and nephroprotective activity of eucalyptus oil on Streptozotocin induced diabetic mice model. Clin Phytoscience. 2018;4(10). Available from: https://doi.org/10.1186/s40816-0180067-X.

33. Slack A, Yeoman A, Wendon J. Renal dysfunction in chronic liver disease. Crit Care. 2010;14(2):214

34. Aldahmash AB, El Nagar MD, Ibrahim EK, Etwaly M. Biotin amelioration of nephrotoxicity in streptozotocin-induced diabetic mice. Saudi J Biosci. 2015; 2(5):564-9.

35. Ohkubo Y, Kishikawa H, Araki E, Miyata T, Isami S, Motoyoshi S, et al. Intensive insulin therapy prevents the progression of diabetic microvascular complications in Japanese patients with non-insulin-dependent diabetes mellitus: a randomized prospective 6-year study. Diabetes Res Clin Pract. 1995;28(2):103-17.

36. Soha M. Hamdy. Effect of Morus Alba Linn extract on enzymatic activities in diabetic rats. J Appl Sci Res. 2012;8(1):10-2.

37. Pari $L$, Latha M. Protective role of Scoparia dulcis plant extract on brain antioxidant status and lipidperoxidation in STZ diabetic male Wistar rats. BMC Complement Altern Med. 2004:4:16.

38. Sugiura M, Ohshima M, Ogawa K, Yano M. Chronic Administration of Satsuma Mandarin Fruit (Citrus unshiu MARC.) improves oxidative stress in Streptozotocin-induced diabetic rat liver. Biol Pharm Bull. 2006;29(3):588-91.

39. Tirgar PR, Jadav PD, Sheth DB, Desai TR. Therapeutic role of anti-oxidant properties of emblica officinalis (amla) in streptozotocin induced type 1 diabetic rats. Pharmacologyonline. 2010;1:728-43.

40. Venukumar MR, Latha MS. Antioxidant activity of curculigo orchioides in carbon tetrachloride-induced hepatopathy in rats. Indian J Clin Biochem. 2002:17(2):80-7.

41. Dröge W. Free radicals in the physiological control of cell function. Physiol Rev. 2002:82(1):47-95.

42. Wiernsperger NF. Oxidative stress as a therapeutic target in diabetes: revisiting the controversy. Diabetes Metab. 2003;26(6):579-85.

43. Al-Shiekh A, Al-Shati A, Sarhan M. Effect of white tea extract on antioxidant enzyme activities of Streptozotocin -induced diabetic rats. Egypt Acad J Biol Sci. 2014;6(2):17-30.

\section{Publisher's Note}

Springer Nature remains neutral with regard to jurisdictional claims in published maps and institutional affiliations.

\section{Submit your manuscript to a SpringerOpen ${ }^{\circ}$ journal and benefit from:}

- Convenient online submission

- Rigorous peer review

- Open access: articles freely available online

High visibility within the field

- Retaining the copyright to your article

Submit your next manuscript at $>$ springeropen.com 